\title{
Political will against funds deficiency: Health Promotion for Older People in Bullgaria
}

\author{
Milena Pavlova ${ }^{1}$, Elka Atanasova $^{2}$, Emanuela Moutafova ${ }^{2}$, \\ Agnieszka Sowa ${ }^{3}$, Iwona Kowalska-Bobko ${ }^{4}$, Alicja Domagała ${ }^{4}$, \\ Stanisława Golinowska ${ }^{3,4}$, Wim Groot ${ }^{5}$
}

\begin{abstract}
${ }^{1}$ Department of Health Services Research, CAPHRI, Maastricht University Medical Center, Faculty of Health, Medicine and Life Sciences, Maastricht University, Maastricht, the Netherlands; ${ }^{2}$ Department of Health Economics and Management, Faculty of Public Health, Medical University of Varna, Varna, Bulgaria; ${ }^{3}$ Department of Social Policy, Institute of Labour and Social Studies, Warsaw, Poland; ${ }^{4}$ Institute of Public Health, Faculty of Health Sciences, Jagiellonian University Medical College, Cracow, Poland; ${ }^{5}$ Department of Health Services Research, CAPHRI, Maastricht University Medical Center, Faculty of Health, Medicine and Life Sciences, Top Institute Evidence-Based Education Research (TIER), Maastricht University, Maastricht, the Netherlands
\end{abstract}

Address for correspondence: Milena Pavlova, Department of Health Services Research, Faculty of Health, Medicine and Life Sciences, Maastricht University, PO Box 616, 6200 MD Maastricht, the Netherlands, +31-43-3881705, m.pavlova@maastrichtuniversity.nl

\section{Authors contribution}

MP and SG designed the concept, MP carried out the data collection and analysis, and drafted the paper, EA, AS, IK and AD commented on the paper and provided additional data, EM, WG and SG reviewed the draft and provided comments for the final version. All authors read and approved the final version submitted.

\section{Acknowledgment}

We would like to thank the Ministry of Regional Development and Public Works in Bulgaria for providing us with country-specific information.

\section{Abstract}

In Bulgaria, health promotion and health education have received less attention in comparison to other public health areas, which has resulted in a small health promotion budget and consequently, in limited health promotion initiatives. This country report draws upon several national reports focused on the Bulgarian health system, and other country specific sources in order to outline the major institutional and financing challenges for health promotion in Bulgaria, and specifically for health promotion for older adults. As evident from this review, the programs and activities oriented toward health promotion for older adults are inconsistent and incomprehensive. The existing programs are mostly in the form of isolated small-scale projects aimed at enabling older workers to reach the statutory retirement, or supporting retired citizens to maintain their health and well-being. Effective strategic vision, coordination and stable funding in the area of health promotion for older adults is indispensable for helping Bulgarian seniors to live longer and healthier.

Key words: public health, health promotion, older adults, health policy, Bullgaria 


\section{Introduction}

Similar to many Eastern European countries, Bulgaria struggles with adverse demographic trends, population health indicators below the EU averages, shortage of public resources, and inefficient health system. Guided by the ambition to improve the population health status, the government recently adopted the Bulgarian National Health Strategy, which attempts to shift the policy focus to the prevention of socially important diseases, raising public awareness on healthy lifestyles and improving the public health networks. This paper provides an overview of the development of the public health legislation in Bulgaria, and outlines the current institutional and financing challenges for health promotion, specifically for health promotion among older adults. The information is gathered through a reviews of key national reports focused on the Bulgarian health system and other country-specific sources. The paper has a policy orientation and targets decision-makers in the region, who could learn from the public health processes in Bulgaria.

\section{Legislation on public health and health promotion generally and for older population}

The first Act on Public Health was adopted in Bulgaria in 1903 and was renewed in 1929. It defined sanitary and anti-epidemic standards as well as activities for combating social diseases [1]. During the communist period, specifically in 1973, a new Public Health Act was adopted, which emphasized environmental protection, behavioral factors, demographic issues and the involvement of the community. This act remained in force until 2005 when the Health Act became effective [2] and is still applied. Among other issues, the act regulates the health protection and health promotion activities, as well as patients' rights. It demonstrates the policy goal to improve the population health and to reach the average European health indicators. Nevertheless, the public health legislation in Bulgaria is continuously undergoing changes, which leads to some gaps and confusions about public health responsibilities [1].

With regard to occupational health, the first policy attention was observed during the communist period when several initiatives focused on the workers' health were implemented within the public enterprises. In 1997, the Law on Health and Safety at Work came into force, which regulates the occupational health services and obliges the employers to assure such services for their employees to minimize work-related health risks [3]. Occupational health services range from surveillance of working environment, evaluation and monitoring of employees' health status to counselling and guidance about health risks and their prevention [1]. However, there are no national-level initiatives on the occupational health of older persons.

Health promotion and health education have received less attentions in comparison to other public health areas. Traditionally, policy priorities have been focused on medical care and treatments. This has not only resulted in a very small health promotion budget but also in limited initiatives in the field of health promotion as well as in the lack of integration between public health programs and other health policy measures [4]. Thus, despite the international collaboration and research projects in Bulgaria, the modern public health and health promotions tools remain largely underutilized [5].

The health promotion interventions mainly focus on healthy behavior as well as on health information, education and communication, training for health professionals, and health surveys among the population and medical staff [1]. There are no major health promotion initiatives specifically focused on older adults.

\section{Health system indicators}

Prior to 1989, Bulgaria had a strongly centralized health system funded primarily by public resources. At present, the health system is transformed into an insurance-based system funded by health insurance contributions, general tax revenue allocated by the government, and a high level of out-of-pocket payments. The limited public resources for health are coupled with major problems in the health and demographic status of the population, as well as with inefficient health system management and poor service provision [6]. While public health services, specifically prevention and health promotion, are declared to be a policy priority [1], their share in the health expenditure is only about $3-4 \%$ (see Table I). In this regard, the Ministry of Health expenditure on prevention and health promotion services is just over $1 \%$ of the total health expenditure. The public health resources are mostly allocated to vaccines and immunizations. Prevention of non-communicable diseases and health promotion account for only about $9 \%$ of the total expenditure on public health services [7].

Overall indicators:

Total health expenditure per capita: 453.89 Euro

Total health expenditure as \% of GDP: $7.87 \%$

Selected function as \% of total health expenditure:

Curative care: $47.13 \%$

Pharmaceuticals and other medical non-durable goods: $42.39 \%$

Rehabilitative care: $1.62 \%$

Preventive care: $2.73 \%$

Healthy condition monitoring programs: $1.70 \%$

Information, education and counseling programs: $0.32 \%$

Immunization programs: $0.23 \%$

Early disease detection programs: $0.49 \%$

Table I. Health system indicators - Bulgaria (data for 2013)

Source: Based on the Eurostat database.

\section{Population aging indicators}

Bulgaria experiences adverse demographic trends due to a low birthrate, high mortality rates and migration to other countries. The population size, which had a pick in 1989 (about 9 million), has been steadily declining and in 2012, the population size was just 7.33 million [8]. This suggests a drop by $18 \%$ which is the highest observed in the EU. The life expectancy at birth is overall low com- 
pared to other EU member states: 71.1 years for males and 78.0 for females (see Table II). As a result of these demographic changes, a rapid aging of the population is observed and this trend is expected to continue to grow. The share of the population $65+$ is foreseen to grow from about $20 \%$ in $2014 / 2015$ to $31.8 \%$ in 2060 and the share of the population $80+$ is foreseen to grow to $12.1 \%$ in 2060. Given this unfavorable trend, the old age dependency ratio $(30.2 \%$ at present) is projected to increase reaching $58.7 \%$ in 2060 .

\begin{tabular}{|l|}
\hline Life expectancy: \\
Life expectancy at birth: 74.5 years \\
Life expectancy at birth males/females: $71.1 / 78.0$ \\
Life expectancy at $65: 16.0$ years \\
Life expectancy at 65 males/females: $14.1 / 17.6$ \\
\hline Healthy life years: \\
Healthy life years at 65 males: 8.7 years \\
Healthy life years at 65 females: 9.6 years \\
\hline Share of older population: \\
Proportion of population aged $65+: 20.0 \%$ of total population \\
Proportion of population aged $80+: 4.6 \%$ of total population \\
Old age dependency ratio $65+: 30.2 \%$ \\
\hline
\end{tabular}

Table II. Population ageing indicators - Bulgaria (data for 2014/2015).

Source: Based on the Eurostat database.

\section{Health status of older population}

The main health indicators in Bulgaria are below the EU averages. The most striking indicator is the comparatively high mortality rate among those aged $40-59$ years. The major and overwhelming mortality causes among the older population are cardiovascular diseases constituting $65 \%$ of deaths in $65+$ males (SDR equal 4787.97 ) and $75 \%$ of deaths in $65+$ females (SDR equal 3670.8 ). Cancers account to $16 \%$ of deaths in older men (SDR equal to 1143.89 ) and $10 \%$ in older women (SDR equal to 564.39). This indicates a substantial scope for health system interventions, particularly in relation to public health and lifestyle changes, especially important in the prevention of cardiovascular diseases. Important concerns are the risk factors related to smoking, alcohol abuse and unhealthy nutrition [1]. Such unhealthy lifestyle trends are observed among older adults as well.

As shown in Table III, a relatively low share of elderly persons in Bulgaria perceives to have long-standing illness and limitations in usual activities due to health problems (about $30-50 \%$ in the age groups below 85 years), but at the same time the mortality rates are high compared to those in other countries. This explains the low healthy life years at the age of 65 years $(8.7$ years for males and 9.6 years for females) compared to other EU member states.
Prevalence of long-standing illness:

Age group 65-74 males/females: 38.3\%/44.4\%

Age group 75-84 males/females: $49.9 \% / 52.3 \%$

Age group $85+$ males/females: $67.3 \% / 68.3 \%$

Self-perceived long-standing limitations in usual activities due to health problems:

Age group 65-74 males/females: 29.6\%/34.3\%

Age group 75-84 males/females: $47.6 \% / 52.5 \%$

Age group $85+$ males/females: $63.4 \% / 73.6 \%$

Table III. Health status of older population - Bulgaria (data for 2014).

Source: Based on the Eurostat and EU-SILC databases.

\section{Potential sources of funding public health and health promotion activities}

Public health services in Bulgaria are mainly funded and provided by the state (see Table IV). This includes all health promotion activities, such as those for elderly persons, but also some prevention services, e.g. services related to health check-ups, check-ups for non-communicable diseases, vaccinations and immunization programs [7]. The Ministry of Health allocates a special annual budget for these promotion, prevention and public health control services. In fact, the branches of the ministry responsible for public health services, so called Regional Health Inspections (RHIs), receive global budgets from the Ministry of Health, calculated based on historical data. This means that the budget of a RHI allocated previous year, is adjusted for inflation and budget growth. However, some services provided by the RHIs are paid directly by the user through user fees (for example, for laboratory tests). There are also public health programs funded and implement by the municipalities.

The following is a list of key public health promotion and education programs implemented at the national level and funded through the state budget allocated to public health [1]:

- National Program for the Limitation of Smoking;

- National Program for the Prevention of Alcohol Abuse;

- National Anti-Drug Strategy;

- National Action Plan for Food and Nutrition;

- National Program for the Prevention and Control of HIV/AIDS and STDs

- National Program for the Prevention and Control of Tuberculosis.

The National Health Insurance Fund (NHIF) finances public health services provided by general practitioners (GPs). The latter services include for example immunization as well as primary prevention and early detection of diseases [9]. The list below shows the basic public health services covered by the NHIF, which are often called prophylaxis services:

- Basic prophylactic examinations and medical tests for determining the health condition of each insured person and for the early diagnosis and detection of diseases; 


\begin{tabular}{|c|c|c|}
\hline Source of funding & Beneficiary & Additional Comments \\
\hline $\begin{array}{l}\text { Taxes } \\
\text { Including } \\
\text { - general taxes }\end{array}$ & $\begin{array}{l}\text { The general public or specific target group who } \\
\text { uses the public health services. }\end{array}$ & $\begin{array}{l}\text { The general tax revenue allocated to public health } \\
\text { is channeled through the branches of the Ministry } \\
\text { of Health or the municipalities. }\end{array}$ \\
\hline $\begin{array}{l}\text { Health insurance premiums } \\
\text { Including } \\
\text { - social insurance } \\
\text { - private insurance }\end{array}$ & $\begin{array}{l}\text { Socially insured patients who use public health } \\
\text { services provided by GPs or specialists. } \\
\text { Mostly foreigners or adults who wish extra insur- } \\
\text { ance. }\end{array}$ & $\begin{array}{l}\text { In addition to insurance premiums, socially insured } \\
\text { patients also pay co-payments for each visit to GP } \\
\text { or medical specialist. } \\
\text { The role of private insurance is minor. }\end{array}$ \\
\hline Other public institutions & $\begin{array}{l}\text { Beneficiaries of public health services provided by } \\
\text { other ministries }\end{array}$ & $\begin{array}{l}\text { e.g. the Ministry of Environment and Water, the } \\
\text { Ministry of Labor and Social Policy }\end{array}$ \\
\hline \multicolumn{3}{|l|}{ Other sources } \\
\hline Funds from the employers & Employees & Company projects or initiatives \\
\hline Households & $\begin{array}{l}\text { Users of services covered by the social insurance or } \\
\text { at the private sector }\end{array}$ & Co-payments or full fees in the private sector \\
\hline Foreign & $\begin{array}{l}\text { International research projects and EU funds } \\
\text { beneficiaries }\end{array}$ & International research projects \\
\hline Others & $\begin{array}{l}\text { Roma communities and patients with chronic } \\
\text { diseases. }\end{array}$ & $\begin{array}{l}\text { Provided by NGOs, including Roma community } \\
\text { organizations and associations of patients with } \\
\text { chronic diseases. }\end{array}$ \\
\hline
\end{tabular}

Table IV. Sources of public health funding in Bulgaria.

Source: Based on own review of literature.

- Additional examinations and tests in relation to the most common diseases typical of a certain age and gender;

- Compulsory periodic medical examinations and tests under the Law on Occupational Health and Safety, defined in Ordinance No 3 of the Ministry of Labor and Social Policy and Ordinance No 14 of the Ministry of Health.

Public health services utilized under the NHIF require co-payments by the patients. Until 2012, the official fee for each outpatient visit to a GP and medical specialist (after a referral) was equal to $1 \%$ of the minimum monthly salary for the country. For hospitalization, the fee amounted to $2 \%$ of the minimum monthly salary per day for the first 10 days of the hospital stay paid once a year. However, in order to reduce the financial burden for the insured people, in 2012, the Council of Ministers replaced the user charges set as a percentage of the minimum monthly salary by fixed copayments. Elderly patients who use services under the NHIF pay the same co-payments as all other patients, unless they fall in one of the exemption categories, e.g. suffering from specific diseases, being disabled, having low-income, etc. There is no exemption for elderly persons only [10]. It should be also mentioned that the public health services (e.g. health check-ups) are underutilized in Bulgaria even when such services are covered by the NHIF.

Nongovernmental organizations (NGOs) such as the Red Cross, various Roma community organizations and associations of patients with chronic diseases also collaborate with the public health institutions in Bulgaria [1]. The NGOs are active in the field of health promotion as well.
Although private health insurance is not well developed in Bulgaria, there are private insurance companies offering health promotion and prevention packages. However, such insurance is mostly purchased by those without health insurance, such as foreigners, or those who wish extra insurance.

\section{Institutional analysis (sectors, organizations and their functions)}

The Ministry of Health is the main decision-makers in the public health area in Bulgaria and is directly accountable for the public health policy in the country. In addition to national health protection programs and state sanitary control, the ministry is also responsible for data collection and preparation of annual health status reports [1]. The national health strategies are integrated into the local level action plans of the regional authorities, and are implemented at the municipal level. The funding for health promotion and disease prevention at the local level is also directly related to these action plans. The implementation approach is individual and context-specific depending on the capacity and resources available at the regional level. Thus, the local-level ministry institutions have the obligation to fulfil the objectives of the national health policies [7].

Various health programs are implemented at the regional level by the 28 RHIs, which are decentralized branches of the Ministry of Health [5]. The RHIs are the most active local stakeholders in the public health area. The work of the RHIs is supervised and coordinated by the Principal State Health Inspector appointed by the Prime Minister at the proposal of the Minister of Health. The inspector also supervises the provision of 
public health services outside the health care system, for example in sectors such as defense, transport, internal affairs and justice [1]. Overall, the following public health functions are carried out with the involvement of regional and local authorities: health screening, disease prevention, health information, health education, enabling social engagement and self-support, sport and recreation activities.

In addition to this, there are several national centers active in the area of public health protection and promotion, such the National Centre of Radiobiology and Radiation Protection, the National Centre of Infectious and Parasitic Diseases, the National Centre of Drug Addictions, the National Centre for Public Health and Analyses. Regional and municipal bodies are also responsible for disease prevention and social protection. Other actors in the health promotion area include the NHIF, Bulgarian Red Cross, NGOs and private insurers. The role of the latter two is however minor.

Overall, the public health activities in Bulgaria are intersectoral and multilevel as the Ministry of Health, RHIs and national centers collaborate with institutions belonging to the Ministry of Environment and Water, the Ministry of Labor and Social Policy, the Ministry of Education, Youth and Science, the Ministry of Agriculture and Foods, the State Agency for Child Protection, as well as with the municipal councils [1]. The general supervision and coordination of health promotion activities is done by the Department of Public Health at the Ministry of Health with regards to national-level programs, and by the Departments of Health Promotion at the RHIs with regards to local-level programs. The National Centre of Public Health and Analyses is also responsible for several national health promotion and education programs [1].

Other organizations that implement health promotion and disease prevention programs, including programs that target modifiable behavioral and social risk factors among older adults (65+ years), include public health associations, patient organizations and organizations for the protection of patients' rights [7].

\section{HPAOP - Health Promotion for Odder People examples of good practices)}

In Bulgaria, there are no special, nationwide health programs aimed at people aged 50+ [8]. Direct financial incentives programs related to health promotion that target the group of elderly persons are also absent. However, some activities in the field of "active aging" could be found in the frame of international projects carried out under programs funded by supranational agencies, municipalities or private companies [7]. Overall these activities are relatively few, scattered and lack sustainability, and their evaluation is only done internally for the purpose of the given activity applying quantitative indicators predominantly.

The following cases describe good practices of occupation-based active aging projects in Bulgaria carried out by employers and municipalities $[3,11]$ :
- Project "SISC - Senior Intergenerational Social Capital" was carried out in Bulgaria in 2008-2011 by the project partner iCENTRES under the coordination of E.Ri.Fo, Italy. The funding was provided through the Lifelong Learning Programme - Gruntdvig. The objective was to equipped senior citizens with skills necessary for coping with changes in order to help them to remain active community members, and to increase their involvement in teaching others (i.e. transferring competence and know-how to younger persons). The project provided e-learning tools for the intergenerational transfer of knowledge, namely skills analysis, identification of strengths and weaknesses, and selection of appropriate trainings to perform the role of a mentor. This helped to strengthen the self-esteem of the participating seniors. The project was equally effective in the other partner countries. It is recognized however, that the universal character of the e-learning tools developed in this project might not fit all settings.

- Project "Age Management in the Company" was carried out in 2004 in Bulgaria by the Bulgarian Telecommunication Company $\mathrm{AD}$, which also provided the project funding. With the participation of trade unions operating in the company, collective bargaining agreement was signed under which the project was launched. The project was addressed to people who worked in the company for at least 10 years and opted for the employment contract termination. Some of the participants were $50+$ years old. The project offered short-term entrepreneurship training organized by the Regional Chambers of Industry and Commerce as well as assistance in business plans preparation and subsidized support for selected entrepreneurial plans. Although the project significantly increased the chances of maintaining the professional activity of the elderly persons, there is no information whether the companies established by workers aged 50+ were sustainable. It is however evident from this project that older people are willing to use the possibilities of prolonging their professional activity.

- Project "Skills Development and Employment Growth of People at the Age Over 50" was carried out in 2009-2011 in the municipality of Kardzhali, Bulgaria. The project was managed by the Business Consult and received funding from the European Social Fund. The main objective was to improve the prospects of employability among unemployed older citizens through skills development. The project consisted of needs analysis, training of participants and internships. As a result of the project, the majority of the participants took up employment within 2 years after the project completion. Thus, the project significantly improved the chances of employment among older citizens. Unlike many other projects that aim at standardized trainings focused on computer skills and basic foreign language skills, the beneficiaries of this project were offered training to undertake a specific occupation. Transferability of such practices is quite high in case the new projects are able to identify the needs of the local labor market. 
It is also necessary to mention the "Back to Work" program, which allows seniors to look after their grandchildren and receive an reimbursement from public funds [8], as well as the Program "Care", which is a recreation subsidized-tourism program offered by hotels in the inactive season to pensioners who are in need of optimizing their physical regime, changing the atmosphere and communication [12]. Also, the Bulgarian municipality of Belogradets participated in the project "Glob@1 Libraries" where village libraries were set up or transformed into training centers for health educations. This initiative is especially relevant for elderly persons in Bulgaria as many of them live in the rural areas.

Another example of a good practice project focused on elderly persons is the project "Telecare Network for Support of Elderly People" [13]. It addresses the needs of older people with disabilities and stimulates NGOs to support this group of elderly persons to deal with risks and maintain social participation through telecare services. The project is located in the Sofia municipality and has received funding under the Bulgarian-Swiss Cooperation Program, Thematic Fund (TF) "Reform Fund Linked to Civil Society Participation" (CSP). The project is implemented by the Institute for Community-Based Social Services Foundation (ICSS). Also the project "Silver City" in the Burgas municipality addressed the needs of older citizens. The project was funded under the Southeast Europe 2007-2013 Network and was a part of the local action plan on active aging.

In the framework of the Operational Program Human Capital 2007-2013, funded by resources form the European Social Fund, there are also various initiatives for improving the quality of care for older and disabled persons. Examples of such initiatives are "Home Care for Independent and Decent Life", "Social Assistant", "Home Help", "Personal Assistant", "Alternatives" and others, with the participation of municipalities, NGOs (e.g. the Red Cross), care providers and the Agency for Social Support [14].

\section{National health promotion policy generally and addressed at the older people}

In Bulgaria, the health policy priorities are defined by the Ministry of Health and are stipulated in the National Health Strategy [1]. The most recent National Health Strategy 2014-2020 has just come into force. The main objectives of the strategy are a healthy nation as well as sustainable, efficient, accessible and high-quality health services [15]. Among other issues, the strategy outlines the need of implementing the "Health in All Policies" approach as well as pro-active, efficient and effective promotional, preventative and rehabilitation programs. The strategy is innovative for the Bulgarian context because it distinguishes age groups with different needs, which should be targeted separately to effectively improve their health status and well-being, and secure their dignity.

A strong centralization is observed with regard to the development and implementation of health promotion and primary prevention-related policies. The main decision-maker in this area is the Ministry of Health. The role of the ministry is to develop and approve all health promotion and disease prevention programs in the country. However, the subsequent execution of these programs is a task of the local level ministry institutions. For this purpose, local level action plans are developed and implemented.

1. The needs of the older population $(65+$ years $)$ in Bulgaria are specifically addressed by the National Strategy for Demographic Development (2012-2030). A key element in this strategy is the promotion of active ageing, namely retaining and developing the labor potential of older persons; encouraging lifelong learning and professional training; promotion of flexible employment for older workers; counteracting the negative attitudes of employers to older workers; encouraging voluntary involvement of older people in society [8].

2. The National Demographic Strategy was complemented by the National Concept for Active Ageing adopted in 2012. It is however solely focused on maintaining the activity of people aged $50+$. The promotion of healthy lifestyles, health improvement and diversification of social services are not sufficiently emphasized [8].

3. In addition to this, in 2012, Bulgaria adopted the National Plan to Promote Active Aging among Elderly in Bulgaria (2012-2030). This was done through a protocol of the Council of Ministers [7]. The plan has the objectives to assure appropriate conditions and equal living opportunities for people $50+$ years old. The plan also aims to promote active aging among the elderly persons in Bulgaria.

4. With the objective to develop the long-term care for elderly persons and to improve their quality of life, in the beginning of 2014, the National Strategy on Long-Term Care was approved. It focuses on setting up a system of home-based long-term care to assure the social inclusion of older persons, as well as the health and care services they need [16].

The Operational Program Human Capital also stipulates measures for older workers aged 55-64. The objective here is to involve older workers as mentors of newly employed people to those jobs. The program also regulates the possibilities for part-time work, flexible working hours, also for older persons. Such options could facilitate the 'transition' of an older employee to retirement through part-time work. A voucher system for financing training in digital technologies and learning languages for people aged $50+$ is also defined in this program $[8,17]$.

The concept of lifelong learning is also integrated in the Vocational Training Strategy and in the Employment Strategy. These programs together with the Operational Program Human Capital mentioned above comprise the National Lifelong Learning Strategy. The overall objective is to upgrade the individual skills and qualifications through training programs offered by universities, private 
training companies and non-profit organizations. The strategy does not target solely people of older working age group but also younger persons [8].

The National Strategy for Reducing Poverty and Promoting Social Inclusion 2020 is relevant for older persons living under the poverty limit. Among other objectives, the strategy also aims to assure the equal access to health services, including public health services, for the poor elderly individuals in Bulgaria [18]. The strategy is related to the new Operational Program Human Capital 2014-2020, which among other things, focuses on the improvement of the employability of older persons.

\section{Conclusions and recommendations}

Public health in Bulgaria shows major gaps due to its past focus on treatment and secondary prevention. It is therefore vital to effectively shift public health activities to health promotion and disease prevention. Health promotion should become an explicit objective not only in policy documents but also in the public health practice. To realize this, the Ministry of Health has the responsibility to assure predictable, stable and adequate funding for health promotion and disease prevention, as well as the implementation of good practices when developing policies on health promotion and disease prevention. Given the expertise gained at the academic level through international cooperation and research, it will be important to involve university staff and research institutes in the evaluation of health promotion and disease prevention programs [7].

The problems in the Bulgarian public health sector outlined in this review, explain the unfavorable health indicators in the country, which are way below the European averages. This suggests even greater challenges for the future public health policy in Bulgaria. As a response to these challenges, the Bulgarian National Health Strategy outlines a number of national targets focusing on the prevention of socially important diseases; raising public awareness on healthy lifestyles; and improving the public health networks. However, this will require systematic monitoring and registration of population health status, which is still problematic in Bulgaria [1]. There is a need for more close collaboration between national, regional and municipal stakeholders in the public health area. The local capacity in the health promotion area needs to be constantly strengthened and supported by the government.

Specifically with regard to older persons, as evident from the above review, the policy and practice oriented toward health promotion targeting this group is inconsistent and incomprehensive. This is not surprising as its legal framework is still being formed and the public health resources are overall limited. The existing programs that can be related to health promotion interventions for older adults are mostly in the form of isolated small-scale projects and mostly aimed at enabling older workers to reach the statutory retirement, or supporting groups of retired citizens in maintaining their health and well-being [8]. Clearly there is a need of coordinated health promotion interventions for older adults with a broader scope taking into account the variety of health determinants. An effective strategic vision and implementation plans, as well as better cross-sectoral coordination and stable funding in the area of health promotion will be vital for helping Bulgarian seniors to live longer and healthier.

\section{References}

1. Dimova A., Rohova M., Moutafova E., Atanasova E., Koeva S., Panteli D., van Ginneken E., Bulgaria: health system review, "Health Systems in Transition" 2012; 14 (3): 1-186, http://www.euro.who.int/_data/assets/pdf_ file/0006/169314/E96624.pdf; accessed: 25.05.2016.

2. Aleksandrova S., The Bulgarian Health Care Reform and Health Act 2004, "Medicine in Law" 2007; 26 (1): 1-14.

3. EU-OSHA, Overview of policies, strategies and programmes in relation to the occupational health and safety of older workers - Bulgaria 2016, https:/oshwiki.eu/wiki/ Overview_of_policies,_strategies_and_programmes_in_relation_to_the_occupational_health_and_safety_of_older_ workers_-_Bulgaria; accessed: 25.05.2016.

4. Dimova A., Popov M., Rohova M., The Health Care Reform in Bulgaria: Analysis. Open Society Institute, Sofia 2007.

5. Scott K.W., Powles J., Thomas H., Rechel B., Perceived barriers to the development of modern public health in Bulgaria: a qualitative study "International Journal of Public Health" 2011; 56 (2): 191-199.

6. Atanasova E., Pavlova M., Velickovski R., Nikov B., Moutafova E., Groot W., What have 10 years of health insurance reforms brought about in Bulgaria? Re-appraising the Health Insurance Act of 1998, "Health Policy" 2011; 102 (2): 263-269.

7. National Center of Public Health and Analyses, Bulgaria country review. JA-CHRODIS - Good Practice in the Field of Health Promotion and Primary Prevention, 2014, http:// www.chrodis.eu/wp-content/uploads/2014/10/JA-CHRO-

DIS_Bulgaria-country-review-in-the-field-of-health-promtion-and-primary-prevention.pdf; accessed: 25.05.2016.

8. Szukalski P., National report - Bulgaria, in: Kryńska E., Szukalski P. (eds), Active ageing measures in selected European Union countries. Final report, 2013: 191-2014, http:// zielonalinia.gov.p1/upload/50plus/Raport-koncowy/Raportkoncowy-50-plus-eng.pdf; accessed: 25.05.2016.

9. NHIF, Health Insurance Act, 2010, http://www.en.nhif. bg/c/document_library/get_file?p_1_id=14818\&folderId=1 8518\&name=DLFE-2002.pdf; accessed: 25.05.2016.

10. Atanasova E., Pavlova M., Groot W., Out-of-pocket patient payments for public health care services in Bulgaria, "Frontiers in Public Health" 2015; 3: 175. doi: 10.3389/ fpubh.2015.00175, http://journal.frontiersin.org/article/10.3389/fpubh.2015.00175/full; accessed: 25.05.2016.

11. Jawor-Joniewicz A., Kornecki J., Wiktorowicz J., Catalogue of good practices in relation to active aging in selected countries of the European Union. Case studies, 2013, http://zielonalinia.gov.pl/upload/50plus/Raport-koncowy/ Katalog-dobrych-praktyk-studia-ENG.pdf; accessed: 25.05.2016 
12. Marinov V., Subsidized tourism and recreation in Bulgaria. Tour Age, 2013, http://www.tourage.eu/; accessed: 25.05.2016.

13. SEE_INNOVA, Telecare Network for Support of Elderly People, 2016, http://www.seeinnova.eu/sites/www.seeinnova.eu/files/page-file-attachments/Telecare $\% 20$ Network $\% 20$ for\%20Support.pdf; accessed: 25-May-2016.

14. Ministry of Labor and Social Policy, National Work Programme on the participation of Bulgaria in the European Year of Active Ageing and Solidarity between Generations - 2012, 2012, http:/ec.europa.eu/social/BlobServlet?docId= 7274\&langId=bg; accessed: 25.05.2016.

15. Ministry of Health, National Health Strategy 2014-2020, 2016, http://www.mh.government.bg/bg/politiki/strate- gii-i-kontseptsii/strategii/nacionalna-zdravna-strategiya-2014-2020/; accessed: 25.05.2016.

16. Ministry of Labor and Social Policy, National Strategy On Long-Term Care, 2014, http://www.mlsp.government. bg/index.php?section=POLICIESI\&I=280; accessed: 25.05.2016.

17. Mladenov T., Statement by Mr. Totyou Mladenov, Minister of Labour and Social Policy, UNECE CONFERENCE ON AGEING, 19-20.09.2112, Vienna.

18. Council of Ministers, National Strategy for Reducing Poverty and Promoting Social Inclusion 2020, 2015, http:// www.strategy.bg/StrategicDocuments/View.aspx?lang=bgBG\&Id=790; accessed: 25.05.2016. 